Correspondence

Hiroaki Minegishi minehiro@toyonet.toyo.ac.jp

\section{Further refinement of the phylogeny of the Halobacteriaceae based on the full-length RNA polymerase subunit $\mathrm{B}^{\prime}\left(r p o B^{\prime}\right)$ gene}

\author{
Hiroaki Minegishi, ${ }^{1}$ Masahiro Kamekura, ${ }^{2}$ Takashi Itoh, ${ }^{3}$ Akinobu Echigo, ${ }^{1}$ \\ Ron Usami ${ }^{1,4}$ and Tetsuo Hashimoto ${ }^{5}$ \\ ${ }^{1}$ Bio-Nano Electronics Research Center, Toyo University, Kawagoe-shi, Saitama, Japan \\ ${ }^{2}$ Halophiles Research Institute, Noda-shi, Chiba, Japan \\ ${ }^{3}$ Japan Collection of Micro-organisms, RIKEN BioResource Center, Wako-shi, Saitama, Japan \\ ${ }^{4}$ Graduate School of Interdisciplinary New Science, Toyo University, Kawagoe-shi, Saitama, Japan \\ ${ }^{5}$ Institute of Biological Sciences, University of Tsukuba, Tsukuba-shi, Ibaraki, Japan
}

A considerable number of species of the Halobacteriaceae possess multiple copies of the 16S gene that exhibit more than $5 \%$ divergence, complicating phylogenetic interpretations. Two additional problems have been pointed out: (i) the genera Haloterrigena and Natrinema show a very close relationship, with some species being shown to overlap in phylogenetic trees reconstructed by the neighbour-joining method, and (ii) alkaliphilic and neutrophilic species of the genus Natrialba form definitely separate clusters in neighbour-joining trees, suggesting that these two clusters could be separated into two genera. In an attempt to solve these problems, the RNA polymerase B' subunit has been used as an additional target molecule for phylogenetic analysis, using partial sequences of $1305 \mathrm{bp}$. In this work, a primer set was designed that consistently amplified the full-length RNA polymerase $B^{\prime}$ subunit gene (rpoB') (1827-1842 bp) from 85 strains in 27 genera of the Halobacteriaceae. Differences in sequence length were found within the first 15 to $31 \mathrm{nt}$, and their downstream sequences (1812 bp) were aligned unambiguously without any gaps or deletions. Phylogenetic trees reconstructed from nucleotide sequences and deduced amino acid sequences by the maximum-likelihood method demonstrated that multiple species/strains in most genera individually formed cohesive clusters. Two discrepancies were observed: (i) the two species of Natronolimnobius were placed in definitely different positions, in that Natronolimnobius innermongolicus was placed in the Haloterrigena/Natrinema cluster, while Natronolimnobius baerhuensis was closely related to Halostagnicola larsenii, and (ii) Natronorubrum tibetense was segregated from the three other Natronorubrum species in the protein tree, while all four species formed a cluster in the gene tree, although supported by a bootstrap value of less than $50 \%$. The six Haloterrigena species/strains and the five species of Natrinema formed a large cluster in both trees, with Halopiger xanaduensis and NIn. innermongolicus located in the cluster in the protein tree and NIn. innermongolicus in the gene tree. Hpg. xanaduensis broke into the cluster of the genus Halobiforma, instead of the Haloterrigena/Natrinema cluster, in the gene tree. The six Natrialba species formed a tight cluster with two subclusters, of neutrophilic species and alkaliphilic species, in both trees. Overall, our data strongly suggest that (i) NIn. innermongolicus is a member of Haloterrigena/Natrinema, (ii) Nrr. tibetense might represent a new genus and (iii) the two genera Haloterrigena and Natrinema might constitute a single genus. As more and more novel species and genera are proposed in the family Halobacteriaceae, the full sequence of the $r p o B^{\prime}$ gene may provide a supplementary tool for determining the phylogenetic position of new isolates. 


\section{INTRODUCTION}

The extremely halophilic, aerobic members of the Archaea are classified within the family Halobacteriaceae, order Halobacteriales in the class Halomebacteria of the phylum Euryarchaeota (http://www.the-icsp.org/taxa/halobacterlist. $\mathrm{htm})$. At the time of writing, the family Halobacteriaceae comprised 27 genera: Haladaptatus (Hap.), Halalkalicoccus (Hac.), Haloarcula (Har.), Halobacterium (Hbt.), Halobaculum (Hbl.), Halobiforma (Hbf.), Halococcus (Hcc.), Haloferax (Hfx.), Halogeometricum (Hgm.), Halomicrobium (Hmc.), Halopiger (Hpg.), Haloplanus (Hpn.), Haloquadratum (Hqr.), Halorhabdus (Hrd.), Halorubrum (Hrr.), Halosarcina (Hsn.), Halosimplex (Hsx.), Halostagnicola (Hst.), Haloterrigena (Htg.), Halovivax (Hvx.), Natrialba (Nab.), Natrinema (Nnm.), Natronobacterium (Nbt.), Natronococcus (Ncc.), Natronolimnobius (Nln.), Natronomonas (Nmn.) and Natronorubrum (Nrr.).

Until a few years ago, it was commonly believed that members of the Halobacteriaceae live only in hypersaline environments such as salt lakes, saline soils, subterranean salt deposits and solar salterns. More recently, it has been suggested that strains of the Halobacteriaceae can grow within saline microniches in non-saline environments, and a novel species, Halosarcina pallida, was isolated from a spring with a low salt concentration (Savage et al., 2007, 2008). Strains of the Halobacteriaceae display physiological and morphological variations. The cells are rods, cocci or flattened triangles or squares. They can be acidophilic (Minegishi et al., 2008), neutrophilic or alkaliphilic. Many strains grow in a simple medium with sucrose and glutamate, or only in a medium containing pyruvate/ glycerol and ammonia, while some strains require 16 amino acids for growth. Most strains lyse instantaneously in hypotonic solution, but some strains survive in $0.5 \%$ salt solution for several days (Fukushima et al., 2007).

Significant intragenomic $16 \mathrm{~S}$ rRNA gene sequence heterogeneity of $2-5 \%$ is a rather common feature of species of the Halobacteriaceae, as first demonstrated by Mylvaganam \& Dennis (1992). Significant heterogeneities have been detected in species of Haladaptatus, Haloarcula, Halobaculum, Halomicrobium, Halorubrum and Halosimplex. Intragenomic heterogeneity of more than $9 \%$ (Cui et al., 2009) may make phylogenetic interpretation of $16 \mathrm{~S}$ rRNA gene sequences very complicated (Boucher et al., 2004).

Two problems have been pointed out in the taxonomy of the Halobacteriaceae based on 16S rRNA gene sequences: (i) the status of the genera Haloterrigena and Natrinema (Tindall, 2003) and (ii) possible separation of alkaliphilic and neutral species of the genus Natrialba (Xu et al., 2001). The genera Haloterrigena and Natrinema were created at almost the same time by Ventosa et al. (1999) and McGenity et al. (1998), respectively. The genus Natrinema included two species, Natrinema pellirubrum and Natrinema pallidum, and a closely related strain, GSL-11. The genus Haloterrigena was established with Haloterrigena turkmenica as the type species, with strain GSL-11 as a strain of $\mathrm{Htg}$. turkmenica, suggesting a close relationship between the two genera. As the numbers of species of the two genera increased, some species were shown to overlap each other in phylogenetic trees reconstructed by the neighbourjoining (NJ) method. Nnm. pellirubrum and Nnm. pallidum were positioned between Haloterrigena strains (Xin et al., 2000; Romano et al., 2007). Another problem is that alkaliphilic and neutrophilic species of the genus Natrialba formed definitely separate clusters in trees reconstructed by the NJ method, suggesting that these two clusters could be separated into two genera (Xu et al., 2001; Itoh et al., 2005).

Thus, there was a need for other targets for chemotaxonomy and complementary molecular markers for the phylogeny of the Halobacteriaceae (Wright, 2006). Recently, the DNA-dependent RNA polymerase subunit $\beta$ (in bacteria) or B (in archaea) gene has become popular as a phylogenetic marker (Dahllöf et al., 2000; Adékambi et al., 2003; Korczak et al., 2004; Case et al., 2007). In members of the Halobacteriaceae, RNA polymerase subunit $\mathrm{B}$ has been shown to be split into smaller subunits, $\mathrm{B}^{\prime \prime}$ and $\mathrm{B}^{\prime}$ (Leffers et al., 1989). The subunits are arranged in the order $\mathrm{H}, \mathrm{B}^{\prime \prime}, \mathrm{B}^{\prime}$ and $\mathrm{A}^{\prime}$. Subunit $\mathrm{B}^{\prime}$ is one of the important components of the transcription apparatus and the gene $\left(r p o B^{\prime}\right)$ is a single-copy conserved gene, highly constrained to evolve at a reasonably slow rate. The fact that only a single copy of each subunit is present in all bacteria and archaea is a tremendous benefit over the 16S rRNA gene for phylogenetic analyses (Acinas et al., 2004; Cilia et al., 1996).

The previous work on $r p o B^{\prime}$ sequencing (1305 bp) of 23 strains of the Halobacteriaceae by Walsh et al. (2004) demonstrated that the RpoB' protein sequence may be an appropriate alternative phylogenetic marker to the $16 \mathrm{~S}$ rRNA gene. They demonstrated that the gene provided a similar degree of phylogenetic resolution as the 16S rRNA gene, yet does not suffer from the problem of paralogy, by showing that compositional bias of the nucleotide and amino acid sequences did not affect their phylogenetic analyses. Subsequently, Enache et al. (2007) accumulated 17 more $r p o B^{\prime}$ gene sequences ( $1305 \mathrm{bp}$, as reported by Walsh et al., 2004). Phylogenetic analysis demonstrated that the $r p o B^{\prime}$ - and $\mathrm{RpoB}^{\prime}$-based phylogenies were mostly congruent with the 16S rRNA gene-based phylogeny, but some incongruence was also observed. However, with some strains, the primers were not able to amplify the $r p o B^{\prime}$ gene, or primers for sequencing the amplified genes did not work.

The phylogenetic analyses by Walsh et al. (2004) and Enache et al. (2007) consistently recovered a monophyletic group, clade I, with high bootstrap support, which was embedded within a collection of less well-resolved lineages in trees based on sequences of the rpoB' gene, the deduced RpoB' protein and the 16S rRNA gene. Clade I consisted of the genera Halobiforma, Haloterrigena, Natrialba, Natrinema, Natronobacterium, Natronococcus, Natronolimnobius and 
Natronorubrum. The available sequences of the genera Haloterrigena and Natrinema formed coherent groups in the NJ trees, suggesting that species of the two genera were very closely related. However, amplification of the $r p o B^{\prime}$ gene from the six other species of Haloterrigena and Natrinema as well as the remaining two species of Natrialba was not successful. To solve these problems, better primers were required.

In this study, we succeeded in designing a primer set and PCR conditions to amplify the whole sequence of the $r p o B^{\prime}$ gene (approx. $1830 \mathrm{bp}$ ), rather than the $1305 \mathrm{bp}$ region, and primers for sequencing reactions. Using the full-length sequences of 89 strains from 26 genera, we inferred phylogenetic trees by the maximum-likelihood (ML) method.

\section{METHODS}

Strains and DNA extraction. Strains used in this study are listed in Supplementary Table S1, available in IJSEM Online. At the time that we finished this study, the genus Halosarcina had not been described, and the authors were not able to obtain strains of several species of a few genera. The strains were cultivated in $3 \mathrm{ml}$ of the media recommended for each strain by the Japan Collection of Microorganisms. Cells were harvested by centrifugation and suspended in TEN buffer $(10 \mathrm{mM}$ Tris/HCl, $\mathrm{pH}$ 8.0, $1 \mathrm{mM}$ EDTA, $100 \mathrm{mM} \mathrm{NaCl}$ ) and $0.3 \mathrm{~g}$ glass beads was added. The cells were broken by shaking for $20 \mathrm{~min}$ on a vortex mixer at maximum speed. Nucleic acids were extracted by phenol/chloroform treatment and ethanol precipitation.

PCR amplification and sequencing of the $r p o B^{\prime}$ gene. An approx. $2 \mathrm{kbp}$ segment from the $3^{\prime}$ end of the $r p o B^{\prime \prime}$ gene to the $5^{\prime}$ end of the rpoA gene was amplified by PCR using the following $50 \mu \mathrm{l}$ mixture: $5 \mu \mathrm{l} 10 \times$ ExTaq PCR buffer, $5 \mu \mathrm{l}$ dNTPs $(2.5 \mathrm{mM}$ each), $1 \mu \mathrm{l}$ forward primer, $1 \mu \mathrm{l}$ reverse primer (100 mM each), $36.5 \mu \mathrm{l}$ distilled water, $0.5 \mu \mathrm{l}$ ExTaq polymerase (TaKaRa) and $1 \mu$ lemplate DNA (about $200 \mathrm{ng}$ DNA). A primer set, HrpoB2 1420F (5'TGTGGGCTNGTGAAGAACTT-3') and HrpoA 153R (5'-GGGTCCATCAGCCCCATGTC- $3^{\prime}$ ), was designed in this work from aligned sequences of the genome regions encoding the $r p o B^{\prime \prime}, r p o B^{\prime}$ and $r p o A^{\prime}$ genes of Halobacterium sp. NRC-1, Haloarcula marismortui ATCC $43049^{\mathrm{T}}$, Haloquadratum walsbyi HBSQ001 and Natronomonas pharaonis DSM $2160^{\mathrm{T}}$ (available at the time we started this work). PCR thermal cycling was carried out in $0.2 \mathrm{ml}$ reaction tubes in a GeneAmp PCR system 9700 (Applied Biosystems). The thermal profile for amplification began with an initial denaturation step $\left(7 \mathrm{~min}, 96{ }^{\circ} \mathrm{C}\right.$ ) followed by 35 cycles of denaturation $\left(1 \mathrm{~min}, 96{ }^{\circ} \mathrm{C}\right.$ ), annealing $\left(1 \mathrm{~min}, 48{ }^{\circ} \mathrm{C}\right)$ and extension $\left(2.5 \mathrm{~min}, 72{ }^{\circ} \mathrm{C}\right)$, followed by a final extension step $\left(7 \mathrm{~min}, 72{ }^{\circ} \mathrm{C}\right)$. Aliquots of $5 \mathrm{ml}$ from the PCR were analysed by agarose gel $(1 \%)$ electrophoresis to confirm the products.

The remainder of the PCR mixture $(45 \mu \mathrm{l})$ was subjected to electrophoresis and the desired DNA fragment was purified and treated with exonuclease I (TaKaRa) and shrimp alkaline phosphatase (Promega). Purified DNA fragments were sequenced using the BigDye Terminator cycle sequencing kit version 3.1 (Pharmacia Biotech) and an ABI Prism 310 Genetic Analyzer (Applied Biosystems). The sequencing primers designed in this study were HrpoB-458F (5'-TTACSATGGGNKCRGGGATG-3'), HrpoB-671R (5'-GCGTCCTCGATGTTGAANCCC-3'), HrpoB-721F (5'-TTCTTCCGNCANTACGAGGG-3'), HrpoB-1148F (5'-AGGAGGACATGC-
CNTTYACC-3'), HrpoB-1166R (5'-GTRAASGGCATGTCCTCCTG$\left.3^{\prime}\right)$ and HrpoB-1457R (5'-ACCATGTGRTASAGYTTSTG-3').

Sequencing of the 16S rRNA gene. The 16S rRNA gene sequences of all strains used in this study had already been deposited in public databases, mostly with lengths of 1471-1475 bp. The quality of some of these sequences was not satisfactory for phylogenetic analyses, however. They were incomplete (1320-1350 bp) or contained many ambiguous nucleotides. The sequences of 12 strains were redetermined in this study by a method described previously (Fukushima et al., 2007) using a primer set to amplify full-length $16 \mathrm{~S}$ rRNA genes: 5'-ATTCCGGTTGATCCTGCCGG-3' (positions 1-20 in the Halobacterium salinarum numbering and 6-25 in the Escherichia coli numbering) and 3'-GACGCCGACCTAGTGGAGGA-5' (Hbt. salinarum 1454-1473; E. coli 1521-1540). The authenticity of this primer set has been proved by the accumulating genome sequences of strains of the Halobacteriaceae. Accession numbers are listed in Supplementary Table S1.

Multiple sequence alignment and phylogenetic analyses. Multiple alignments of the gene sequences were done using CLUSTAL_X version 2.0.9 (Larkin et al., 2007) and edited manually, if required in the case of $16 \mathrm{~S}$ rRNA gene sequences, to remove gaps and ambiguously aligned characters. The $r p o B^{\prime}$ gene sequences were translated into amino acid sequences by EnzymeX version 3.1 (http:// mekentosj.com). Pairwise sequence similarities were calculated with GENETYX-MAC version 14.0.11 (GENETYX Corporation). ML analyses were performed with RAxML version 2.2.3, using the GTR $+\Gamma$ and WAG $+\Gamma$ models, respectively, for the nucleotide and amino acid sequence-based analyses (Stamatakis et al., 2005). Support values for internal branches of the ML tree were obtained by bootstrapping (1000 and 100 replicates for nucleotide and amino acid sequencebased analyses, respectively) using the GTR $+\Gamma$ and WAG $+\Gamma$ models, respectively (Stamatakis et al., 2005). The CONSENSE program in the PHYLIP package (http://evolution.gs.washington.edu/phylip. html) was used to calculate bootstrap values.

First, analyses of the $r p o B^{\prime}$ gene and $\mathrm{RpoB}^{\prime}$ protein were performed by using 89 sequences. Second, based on the results of the first analyses, relationships among 34 species from clade I, which was redefined in this work (see Results), were analysed by using eight outgroup species. An optimal ML tree based on 16S rRNA gene sequences was also obtained by using the same taxon sampling.

Nucleotide and amino acid compositions for individual datasets were calculated and compared by a chi-squared test using the PUZZLE program (Schmidt et al., 2002). The approximately unbiased (AU) test (Shimodaira, 2002) in the CONSEL program (Shimodaira \& Hasegawa, 2001) was used for statistical comparisons among alternative trees of interest. The significance level was set at $P<0.05$.

\section{RESULTS}

\section{Alignment of rpo $B^{\prime}$ gene sequences}

Several sets of degenerate primers were designed based on an alignment of the sequences of RNA polymerase gene subunits $\mathrm{B}^{\prime \prime}, \mathrm{B}^{\prime}$ and $\mathrm{A}$ of the four strains of the Halobacteriaceae whose genome sequences were available. Primers HrpoB2-1420F/HrpoA-153R were chosen because they consistently produced a single PCR product of the expected size $(1.9 \mathrm{~kb})$. The sequences upstream of the ATG corresponding to the $\mathrm{N}$-terminal methionine and downstream of the termination codon were trimmed off, and the full-length $r p o B^{\prime}$ sequences were translated into amino acid 


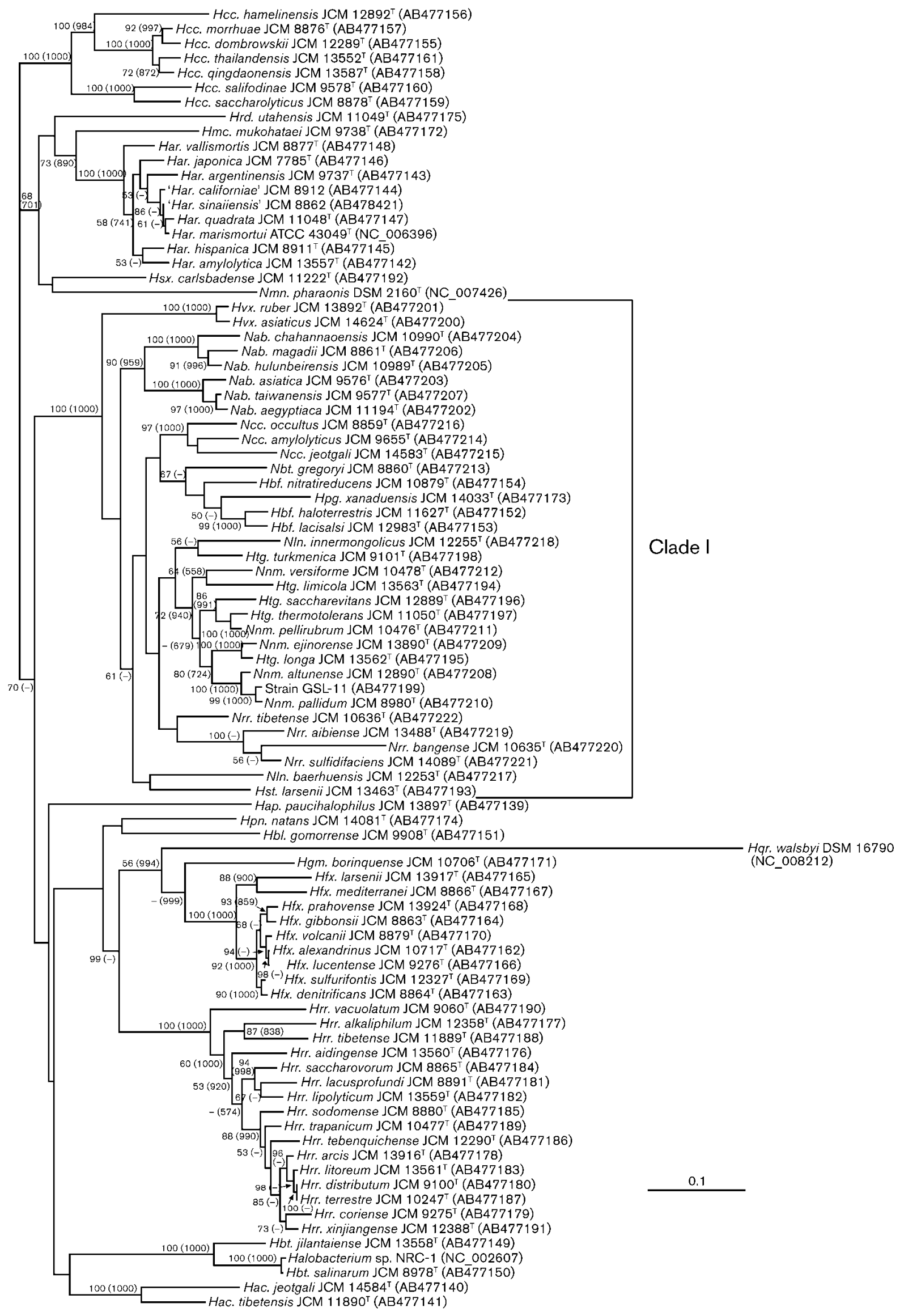


Fig. 1. Optimal $M L$ tree inferred from an $r p o B^{\prime}$ DNA sequence alignment for the Halobacteriaceae. The evolutionary model employed in the analysis was GTR $+\Gamma$. Support for nodes corresponds to bootstrap values for 100 replicates; only values greater than 50 are displayed. Clade $\mathrm{I}$ is indicated. Bootstrap values from the $\mathrm{NJ}$ analysis are shown in parentheses.

sequences. The lengths of the $85 r p o B^{\prime}$ sequences determined in this study and the four derived from the genome sequences were $1827 \mathrm{bp}$ (18 sequences), $1830 \mathrm{bp}$ (59), $1833 \mathrm{bp}$ (four), $1836 \mathrm{bp}$ (four) and $1842 \mathrm{bp}$ (one). The gene lengths of species of genera with multiple species were the same, except for the genus Halococcus, which varied from 1827 to 1842 bp (Supplementary Table S1). Alignment of the deduced amino acid sequences, however, demonstrated clearly that the differences among sequence lengths were not inside the RpoB' coding sequence, but were concentrated within the first 15-31 nt. The downstream sequences [1812 bp, beginning with the sequence CGMGAMGC, or $\mathrm{RD}(\mathrm{E}) \mathrm{A}$ in amino acid sequences] were aligned unambiguously without any gaps or deletions until the $3^{\prime}$ termini.

\section{Phylogenetic trees based on 89 sequences of the $r p o B^{\prime}$ gene and the RpoB' protein}

Phylogenetic trees reconstructed from nucleotide sequences (Fig. 1) and deduced amino acid sequences (Fig. 2) by the ML method demonstrated that the sequences of the six genera outside clade 1 that were represented by multiple species/strains formed cohesive clusters individually: Halococcus (seven species), Haloarcula (seven species and two strains), Haloferax (nine species), Halorubrum (16 species), Halobacterium (two species and one strain) and Halalkalicoccus (two species).

The species of the problematic genera described in the Introduction, Haloterrigena, Natrinema and Natrialba, were included in clade I (indicated in Figs 1 and 2; Walsh et al., 2004; Enache et al., 2007). In these trees, species of the recently described genera Halopiger, Halostagnicola and Halovivax were also shown to constitute a monophyletic group with clade I with high bootstrap support (100 and $96 \%$, respectively, for Figs 1 and 2) and, thus, clade I was redefined to include these three genera, i.e. 34 species of 11 genera.

The six Natrialba species formed a tight cluster in the gene tree (Fig. 1) with two subclusters, of three neutrophilic species and three alkaliphilic species. The protein tree (Fig. 2) also reconstructed the same relationship, but bootstrap support for the monophyly of Natrialba and for the separation of the neutrophilic and alkaliphilic species was not high.

Two further discrepancies were apparent within clade I, in addition to the problems of Haloterrigena/Natrinema and Natrialba. (i) The two species of the genus Natronolimnobius were placed in definitely different positions and (ii) Natronorubrum tibetense was segregated from the other three species of the genus in the RpoB' tree (Fig. 2). The interrelationships of the Haloterrigena/Natrinema cluster are described below.

\section{Trees for clade I}

By focusing on the subtree of the redefined clade I and eight outgroup species (of genera Halococcus, Halalkalicoccus and Halobacterium), the interrelationships within clade I were further analysed individually by the ML method using the sequences of the $r p o B^{\prime}$ gene, the RpoB' protein and the $16 \mathrm{~S}$ rRNA gene (Fig. 3).

In the $r p o B^{\prime}$ gene and $\mathrm{RpoB}^{\prime}$ phylogenies, two discrepancies between phylogeny and taxonomy were apparent within clade I. Firstly, Natronolimnobius innermongolicus was located within the Haloterrigena/Natrinema cluster, while Natronolimnobius baerhuensis was located as a sister group to Halostagnicola larsenii, although both had no clear bootstrap support. Secondly, Nrr. tibetense was segregated from the other three species of the genus in the RpoB' analysis, while the four Natronorubrum species formed a cluster in the $r p o B^{\prime}$ gene tree, although the bootstrap support was less than $50 \%$.

In the $16 \mathrm{~S}$ rRNA gene tree (Fig. 3c), however, all species of the genera Natronolimnobius and Natronorubrum formed clusters with more than $90 \%$ bootstrap support. On the other hand, neither Haloterrigena nor Natrinema was monophyletic; the 11 sequences of Haloterrigena/Natrinema strains formed a loose clade, though with no clear bootstrap support.

The chi-squared test performed by the PUZZLE program showed that no compositional bias was detected for the deduced amino acid sequences of the RpoB' protein or the 16S rRNA gene sequences of the 42 species, while significantly different compositions were detected for $\mathrm{Hbt}$. salinarum $(P=0.0129)$ and Nln. baerhuensis $(P=0.0288)$ in the $r p o B^{\prime}$ gene analysis. Hbt. salinarum was one of the outgroup species in this analysis, and its base compositional bias may therefore not contribute much to the phylogeny of the ingroup. The significantly different base composition in $N \ln$. baerhuensis could not be the reason for the failure of the two Natronolimnobius species to form a clade, since the amino acid-based RpoB' phylogeny also failed to reconstruct the monophyly of Natronolimnobius.

In order to address the three problems of Natronolimnobius, Natronorubrum and Haloterrigena/Natrinema, the tree of clade I was further analysed by using statistical tests. The AU test was performed to detect the significance of the loglikelihood differences between each optimal tree in the analysis of the RpoB', $r p o B^{\prime}$ gene or $16 \mathrm{~S}$ rRNA gene datasets (Fig. 3) and five alternative trees of interest (see Table 1).

(i) If Nln. innermongolicus was constrained to the branch leading to Nln. baerhuensis (tree 1 of Table 1), the loglikelihood difference was significant $(P<0.01)$ in the RpoB' protein analysis while, in the $r p o B^{\prime}$ gene analysis, tree 1 was 


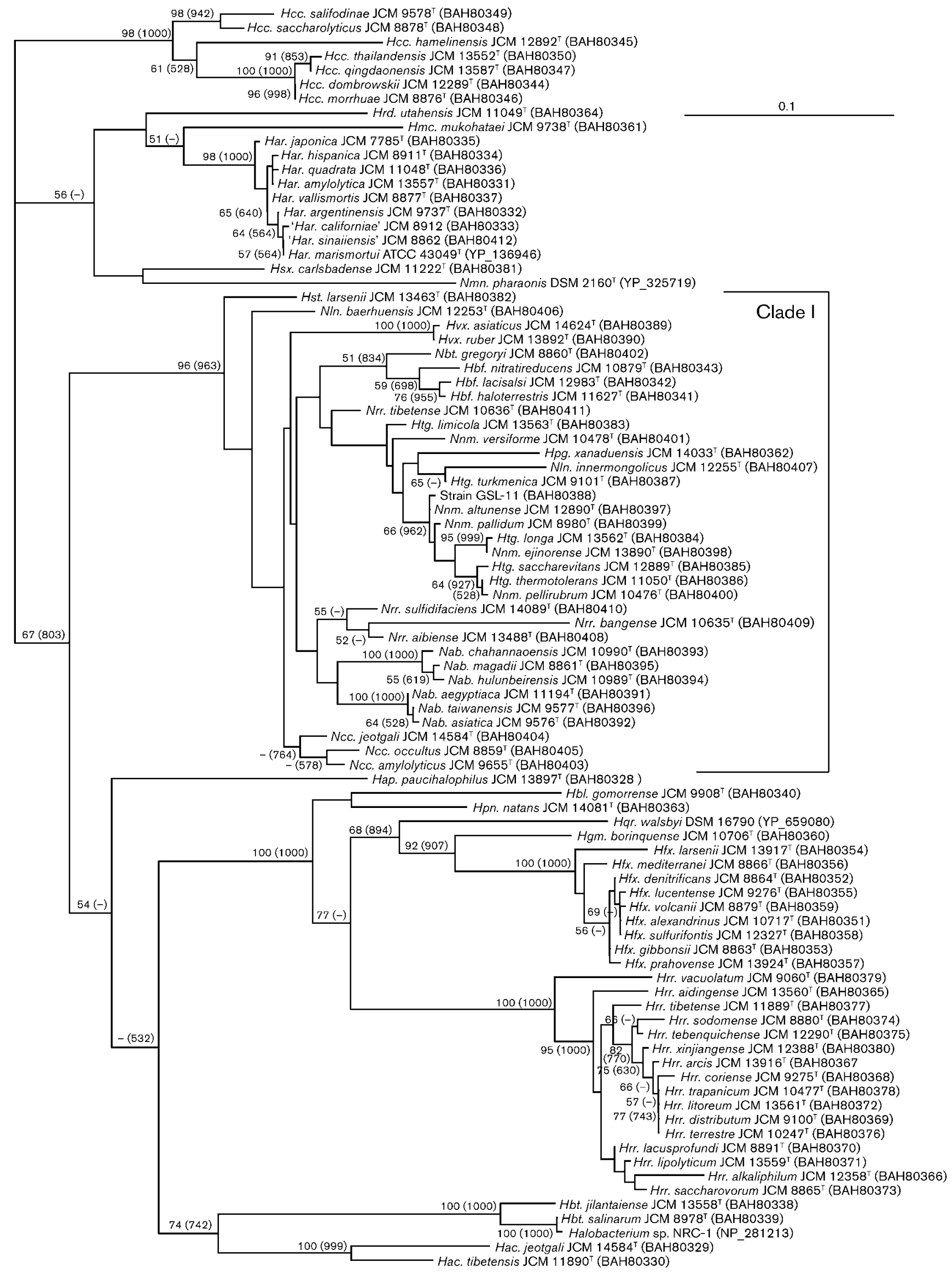


Fig. 2. Optimal $M L$ tree inferred from deduced $\mathrm{RpoB}^{\prime}$ protein sequences for the family Halobacteriaceae. The evolutionary model employed in the analysis was $W A G+\Gamma$. See legend to Fig. 1 for further details.

also unlikely, but statistical significance could not be detected for the log-likelihood difference between the tree in Fig. 3(a) and tree $1(P=0.062)$. If $N \ln$. baerhuensis was constrained to the Nln. innermongolicus branch (tree 2), the log-likelihood difference was significant in the analyses of both the $r p o B^{\prime}$ gene and the RpoB' protein $(P<0.001$ and $<0.01$, respectively). These results suggest that Nln. innermongolicus was unlikely to be monophyletic with $N \ln$. baerhuensis.

(ii) If Nrr. tibetense was constrained to the common ancestor of the other three Natronorubrum species (tree 3) in the RpoB' analysis, the log-likelihood difference of tree 3 from that of the tree in Fig. 3(b) was not significant $(P=0.299)$, while, if the common ancestor of the other three Natronorubrum species was moved to a branch leading to Nrr. tibetense (tree 4), the log-likelihood difference was also not significant $(P=0.186)$, suggesting that we could not exclude the possibility that Nrr. tibetense is monophyletic with the other Natronorubrum species, as is reconstructed by the $r p o B^{\prime}$ gene analysis.

(iii) If constraints were made to separate the genera Natrinema and Haloterrigena clearly, as shown in Supplementary Fig. S1 (tree 5), the log-likelihood difference was highly significant $(P<0.001)$ in all three analyses, demonstrating that neither of the genera Natrinema and Haloterrigena is monophyletic.

\section{Similarities of $r p o B^{\prime}$ gene sequences within genera}

Similarities were calculated for the $1812 \mathrm{bp} r p o B^{\prime}$ gene sequences amongst species within each genus. The lowest similarities in each genus were as follows: Halalkalicoccus, 89.1\%; Haloarcula, 94.4\%; Halobacterium, $91.4 \%$; Halobiforma, 92.1\%; Halococcus, $86.0 \%$; Haloferax, $92.1 \%$; Halorubrum, 88.5\%; Haloterrigena, $90.1 \%$; Halovivax, 97.8 \%; Natrialba, 88.5\%; Natrinema, $92.2 \%$; and Natronococcus, $91.3 \%$. Similarities amongst species of Natronorubrum excluding Nrr. tibetense were $88.1 \%$. A similarity matrix (Supplementary Table S2) showed that the pairwise similarities amongst the type species of 26 genera ranged from $70.4 \%$ (between Halopiger xanaduensis and Hqr. walsbyi) to $91.9 \%$ (between Htg. turkmenica and Nnm. pellirubrum).

Genome sequences of nine strains of the Halobacteriaceae are now available: Haloarcula marismortui ATCC $43049^{\mathrm{T}}$, Halobacterium sp. NRC-1, Hbt. salinarum R1, Haloferax volcanii DS2, Halomicrobium mukohataei DSM $12286^{\mathrm{T}}$, Haloquadratum walsbyi HBSQ001, Halorhabdus utahensis DSM $12940^{\mathrm{T}}$, Halorubrum lacusprofundi ATCC $49239^{\mathrm{T}}$ and Natronomonas pharaonis DSM $2160^{\mathrm{T}}$. The nine rpoB" gene sequences ranged in length from 1563 to $1578 \mathrm{bp}$. The 5' regions were perfectly aligned without any gaps, and the differences were concentrated in positions 1534-1545. Appropriate deletion was done by consulting aligned deduced amino acid sequences, and unambiguous rpo $B^{\prime \prime}$ sequences of $1566 \mathrm{bp}$ were concatenated with the $1812 \mathrm{bp}$ $r p o B^{\prime}$ sequences. Similarities of the concatenated 3378 bp sequences amongst species of different genera ranged from $71.1 \%$ (Hqr. walsbyi vs Hrd. utahensis) to $86.2 \%$ (Har. marismortui vs Hmc. mukohataei).

\section{DISCUSSION}

In this study, we have designed an excellent amplification primer set and eight sequencing primers that worked perfectly to determine full-length sequences of the $r p o B^{\prime}$ genes of 85 strains of the Halobacteriaceae. The previous phylogenetic analyses by Walsh et al. (2004) and Enache et al. (2007) were performed on partial (1305 bp) rpo $B^{\prime}$ gene sequences. Enache et al. (2007) pointed out a few important problems. In an $r p o B^{\prime}$ gene tree reconstructed by the NJ method, the four species of the genus Natrialba analysed at that time formed a cluster, while, in an RpoB' protein tree, the three alkaliphilic species of the genus Natrialba formed a tight group, while a neutrophilic species, Natrialba asiatica, formed a separate group with species of genera Natronorubrum and Natronolimnobius. Similar NJ trees reconstructed from 16S rRNA gene sequences had been published before (Xu et al., 2001; Itoh et al., 2005), suggesting a possible separation of the alkaliphilic and neutrophilic species into two genera. In the present study, we determined the full-length $r p o B^{\prime}$ sequences of all six species of the genus Natrialba. In an $r p o B^{\prime} \mathrm{NJ}$ tree (not shown) reconstructed from the same dataset used for Fig. 1, a tight cluster was obtained consisting of the six species, while, in an $\mathrm{RpoB}^{\prime}$ protein NJ tree (not shown), the three alkaliphilic species formed a tight group and the three neutrophilic species formed a separate group on a branch with species of genera Natronorubrum. In all of our ML trees (Figs 1, 2 and 3), however, the monophyly of the genus Natrialba was reconstructed, but the support for the clade differed significantly between the analyses. High bootstrap support (more than $90 \%$ ) was detected in the $r p o B^{\prime}$ gene analysis (Fig. 1 and Fig. 3a). An ML tree based on 16S rRNA gene sequences (Supplementary Fig. S2) supported the monophyly of all species, while an NJ tree (Supplementary Fig. S3) gave different topologies of the alkaliphilic and neutrophilic species. Further data and analyses would be necessary to confirm the monophyly of Natrialba robustly.

Another problem posed by Enache et al. (2007) concerns the genus Natronorubrum. They showed that Nrr. tibetense differed from the other two species included in their study in NJ trees. Our ML protein tree showed a similar topology (Fig. 1), but the four Natronorubrum species formed a 


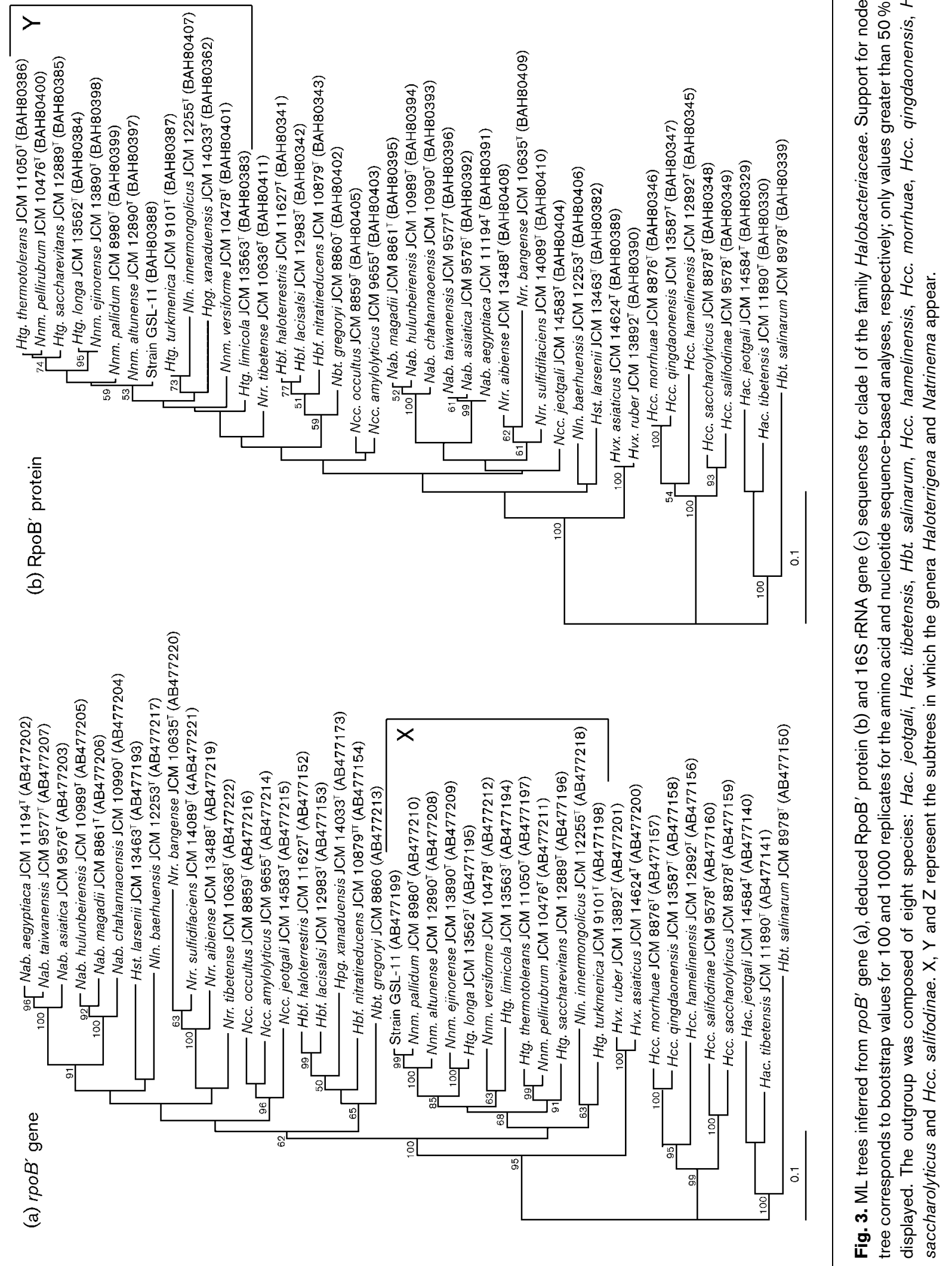


(c) $16 \mathrm{~S}$ rRNA gene

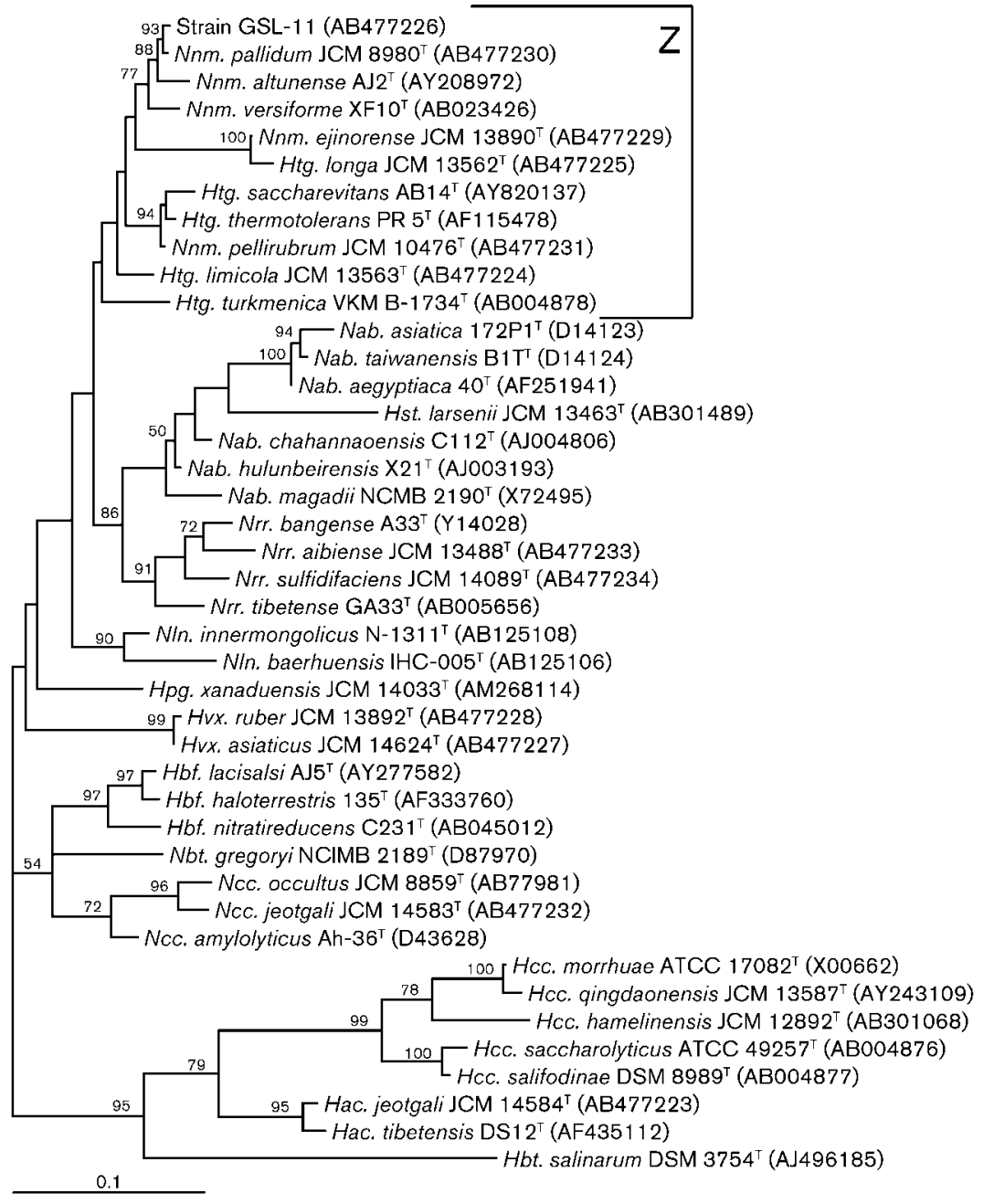

cluster in the $r p o B^{\prime}$ and $16 \mathrm{~S}$ rRNA gene trees (Supplementary Figs S2 and S3). At present, it is not possible to draw any definite conclusions from the available dataset.
However, it is noteworthy that our AU test-based analyses for $r p o B^{\prime}$ did not reject the monophyly of Natronorubrum (Table 1).

Table 1. AU tests of log-likelihood differences between each optimal tree and alternative trees of interest

The AU test was performed to detect the significance of log-likelihood differences between each optimal tree in analyses of the rpoB' gene, RpoB' protein or 16S rRNA gene dataset and five alternative trees of interest. Tree 1, Nln. innermongolicus was removed to the position of Nln. baerhuensis; tree 2, Nln. baerhuensis to Nln. innermongolicus; tree 3, Nrr. tibetense to the common ancestor of the other Natronorubrum species; tree 4, the common ancestor of the other Natronorubrum species to Nrr. tibetense; tree 5, the species of Haloterrigena were separated from those of Natrinema. $\Delta$ indicates the log-likelihood differences of alternative topologies from each optimal ML tree (Fig. 3). $P$-values of the AU test were estimated by CONSEL.

\begin{tabular}{|c|c|c|c|c|c|c|c|}
\hline \multirow[t]{2}{*}{ Tree } & \multirow[t]{2}{*}{ Topological alteration } & \multicolumn{2}{|c|}{$r p o B^{\prime}$ gene } & \multicolumn{2}{|c|}{ RpoB' $^{\prime}$ protein } & \multicolumn{2}{|c|}{$16 S$ rRNA gene } \\
\hline & & $\Delta$ & $\boldsymbol{P}$ & $\Delta$ & $P$ & $\Delta$ & $P$ \\
\hline 1 & Nln. innermongolicus $\rightarrow N \ln$. baerhuensis & 30.5 & 0.062 & 52.5 & 0.001 & - & - \\
\hline 2 & Nln. baerhuensis $\rightarrow N \ln$. innermongolicus & 70.6 & $2.00 \mathrm{E}-04$ & 57.2 & 0.001 & - & - \\
\hline 3 & Nrr. tibetense $\longrightarrow$ other Natronorubrum species & - & - & 8.6 & 0.299 & - & - \\
\hline 4 & Other Natronorubrum species $\rightarrow N r r$. tibetense & - & - & 12.1 & 0.186 & - & - \\
\hline 5 & Haloterrigena species $\rightarrow$ Natrinema species & 535.6 & $1.00 \mathrm{E}-03$ & 125.6 & $1.00 \mathrm{E}-09$ & 249.6 & $2.00 \mathrm{E}-67$ \\
\hline
\end{tabular}


In the $\mathrm{NJ}$ gene and protein trees reconstructed by Enache et al. (2007), the type strains of the two species of the genus Natronolimnobius behaved as very close relatives (99.8 and $99.3 \%$ similarity, respectively), although the similarity of their $16 \mathrm{~S}$ rRNA gene sequences is $95.9 \%$. Nln. baerhuensis has two known strains, JCM $12253^{\mathrm{T}}$ and JCM 12254, while Nln. innermongolicus consists of one strain, JCM $12255^{\mathrm{T}}$. In the present study, we prepared fresh DNA from new ampoules of JCM $12253^{\mathrm{T}}$ and JCM $12255^{\mathrm{T}}$. The sequences obtained in our study clearly demonstrated that the sequence represented by GenBank accession no. AB295636 of Nln. innermongolicus JCM $12255^{\mathrm{T}}$ was wrong, and the two type strains, JCM $12253^{\mathrm{T}}$ and JCM $12255^{\mathrm{T}}$, were statistically significantly split in individual analyses of $\mathrm{RpoB}^{\prime}$ protein (Fig. 3b and Table 1) and $r p o B^{\prime}$ gene (Fig. $3 \mathrm{a}$ and Table 1) sequences, suggesting strongly that the $r p o B^{\prime}$ (RpoB') sequences of Nln. baerhuensis and Nln. innermongolicus are not monophyletic.

The biggest problem in clade I is the issue of Haloterrigena and Natrinema. In this paper, full-length $r p o B^{\prime}$ genes were amplified from all species of the two genera. The three ML trees based on our data showed that the six Haloterrigena species/strains and the five Natrinema species formed a loose, intercrossing cluster (Figs 1,2 and 3). Species of Haloterrigena and Natrinema never formed individual clusters, suggesting that the species of the two genera might constitute a single genus. The trees also suggested that Nln. innermongolicus should be incorporated into the Haloterrigena/Natrinema cluster if the species of the two genera are merged in future. It may be worth pointing out here that, in 16S rRNA gene NJ trees published in recent papers proposing novel species of the genera Haloterrigena and Natrinema, incomplete sequences as short as $1344 \mathrm{bp}$ or sequences with 18-20 ambiguous bases have been used, giving a seemingly rational separation of the two genera. Our Supplementary Figs S2 and S3 reconstructed in this study, based on sequences longer than 1421 bp with very few ambiguous bases, clearly demonstrate the intercrossing between Haloterrigena and Natrinema species. A problematic observation is the wide range of $\mathrm{G}+\mathrm{C}$ contents, from $59.8 \mathrm{~mol} \%$ in Htg. turkmenica VKM B- $1734^{\mathrm{T}}$ (Ventosa et al., 1999) to $69.9 \mathrm{~mol} \%$ for the major DNA component (60.0 mol\% for the minor component) of Nnm. pellirubrum (McGenity et al., 1998; Ross \& Grant, 1985). This range of values far exceeds that commonly encountered within a single genus. It is noteworthy that the $\mathrm{G}+\mathrm{C}$ content range of species of the genus Halobacterium has recently been widened: Halobacterium piscisalsi, $65.5 \mathrm{~mol} \%$; Hbt. salinarum, 67.1-71.2 mol\% (Grant et al., 2001); Hbt. jilantaiense, $64.2 \mathrm{~mol} \%$; Hbt. noricense, $54.5 \mathrm{~mol} \%$. Future studies are needed to resolve this issue.

Quite recently, a challenging paper was published by Adékambi et al. (2008). They compared published values for DNA-DNA hybridization of strains of 230 bacterial species representative of 45 genera with similarity of $r p o B$ gene sequences (3400-4100 bp) retrieved from GenBank. They observed that an $r p o B$ gene sequence similarity of less than $85.5 \%$ correlated with membership of different genera. Our present phylogenetic analyses are based on gene sequences of rpoB' (approx. $1830 \mathrm{bp}$ ), a smaller subunit of RpoB in the Halobacteriaceae. We calculated similarities of $1812 \mathrm{bp} r p o B^{\prime}$ gene sequences amongst species/strains within each genus (see Results). The genus Haloarcula, with the highest similarities, more than $94.4 \%$, gave a very tight cluster with short branches in Figs 1 and 2. On the other hand, the cluster of the genus Halococcus was very loose, with long branches within the cluster, reflecting similarities as low as $86-87 \%$. This may suggest that the species of the genus Halococcus could be divided into different genera if differentiating characteristics between them are recognized. Calculation of similarities amongst the type species of 26 genera (Supplementary Table S2) showed that the highest value was obtained between $\mathrm{Htg}$. turkmenica and Nnm. pellirubrum, suggesting very strongly that the two genera could be merged into a single genus.

According to the genome sequences, only single copies of the $r p o B^{\prime \prime}$ and $r p o B^{\prime}$ genes are present in the nine strains of the Halobacteriaceae mentioned in the Results. Similarities amongst the nine concatenated $r p o B^{\prime \prime}$ and $r p o B^{\prime}$ gene sequences (3378 bp) were less than $86.2 \%$, the value between Har. marismortui and Hmc. mukohataei. The value of $86.2 \%$ is very close to that of $85.5 \%$ detected in bacterial strains (Adékambi et al., 2008), and may serve as a critical value for differentiation of genera of the Halobacteriaceae. Full-length sequences of $r p o B^{\prime \prime}$ and $r p o B^{\prime}$ genes of all strains of clade I may suggest clearer solutions to the long-standing problems in the family Halobacteriaceae discussed above.

As more and more novel species and genera are proposed in the family Halobacteriaceae, full-length sequences of the $r p o B^{\prime}$ gene may be useful as a supplementary tool in determining the phylogenetic position of new isolates.

\section{REFERENCES}

Acinas, S. G., Marcelino, A. L., Klepac-Ceraj, V. \& Polz, F. M. (2004). Divergence and redundancy of $16 \mathrm{~S}$ rRNA sequences in genomes with multiple rrn operons. J Bacteriol 186, 2629-2635.

Adékambi, T., Colson, P. \& Drancourt, M. (2003). rpoB-based identification of nonpigmented and late-pigmenting rapidly growing mycobacteria. J Clin Microbiol 41, 5699-5708.

Adékambi, T., Shinnick, T. M., Raoult, D. \& Drancourt, M. (2008). Complete $r p o B$ gene sequencing as a suitable supplement to DNADNA hybridization for bacterial species and genus delineation. Int $J$ Syst Evol Microbiol 58, 1807-1814.

Boucher, Y., Douady, C. J., Sharma, A. K., Kamekura, M. \& Doolittle, W. F. (2004). Intragenomic heterogeneity and intergenomic recombination among haloarchaeal ribosomal RNA genes. J Bacteriol 186, 3980-3990.

Case, R. J., Boucher, Y., Dahllöf, l., Holmström, C., Doolittle, W. F. \& Kjelleberg, S. (2007). Use of $16 \mathrm{~S}$ rRNA and $r p o B$ genes as molecular markers for microbial ecology studies. Appl Environ Microbiol 73, 278-288.

Cilia, V., Lafay, B. \& Christen, R. (1996). Sequence heterogeneities among $16 \mathrm{~S}$ ribosomal RNA sequences, and their effect on phylogenetic analyses at the species level. Mol Biol Evol 13, 451-461. 
Cui, H.-L., Zhou, P.-J., Oren, A. \& Liu, S.-J. (2009). Intraspecific polymorphism of $16 \mathrm{~S}$ rRNA genes in two halophilic archaeal genera, Haloarcula and Halomicrobium. Extremophiles 13, 31-37.

Dahllöf, I., Baillie, H. \& Kjelleberg, S. (2000). rpoB-based microbial community analysis avoids limitations inherent in 16S rRNA gene intraspecies heterogeneity. Appl Environ Microbiol 66, 3376-3380.

Enache, M., Itoh, T., Fukushima, T., Usami, R., Dumitru, L. \& Kamekura, M. (2007). Phylogenetic relationships within the family Halobacteriaceae inferred from $r p o B^{\prime}$ gene and protein sequences. Int J Syst Evol Microbiol 57, 2289-2295.

Fukushima, T., Usami, R. \& Kamekura, M. (2007). A traditional Japanese-style salt field is a niche for haloarchaeal strains that can survive in $0.5 \%$ salt solution. Saline Syst 3, 2.

Grant, W. D., Kamekura, M., McGenity, T. J. \& Ventosa, A. (2001). Class III. Halobacteria class. nov. In Bergey's Manual of Systematic Bacteriology, 2nd edn, vol. 1, pp. 294-334. Edited by D. R. Boone, R. W. Castenholz \& G. M. Garrity. New York: Springer.

Itoh, T., Yamaguchi, T., Zhou, P. \& Takashina, T. (2005). Natronolimnobius baerhuensis gen. nov., sp. nov. and Natronolimnobius innermongolicus sp. nov., novel haloalkaliphilic archaea isolated from soda lakes in Inner Mongolia, China. Extremophiles 9, 111-116.

Korczak, B., Christensen, H., Elmer, S., Frey, J. \& Kuhnert, P. (2004). Phylogeny of the family Pasteurellaceae based on $r p o B$ sequences. In $\mathrm{J}$ Syst Evol Microbiol 54, 1393-1399.

Larkin, M. A., Blackshields, G., Brown, N. P., Chenna, R., McGettigan, P. A., McWilliam, H., Valentin, F., Wallace, I. M., Wilm, A. \& other authors (2007). CLUSTAL $W$ and CLUSTAL_X version 2.0. Bioinformatics 23, 2947-2948.

Leffers, H., Gropp, F., Lottspeich, F., Zillig, W. \& Garret, R. A. (1989). Sequence, organization, transcription and evolution of RNA polymerase subunit genes from the archaebacterial extreme halophiles Halobacterium halobium and Halococcus morrhuae. J Mol Biol 206, $1-17$.

McGenity, T. J., Gemmell, R. T. \& Grant, W. D. (1998). Proposal of a new halobacterial genus Natrinema gen. nov., with two species Natrinema pellirubrum nom. nov. and Natrinema pallidum nom. nov. Int J Syst Bacteriol 48, 1187-1196.

Minegishi, H., Mizuki, T., Echigo, A., Fukushima, T., Kamekura, M. \& Usami, R. (2008). Acidophilic haloarchaeal strains are isolated from various solar salts. Saline Syst 4, 16.

Mylvaganam, S. \& Dennis, P. P. (1992). Sequence heterogeneity between the two genes encoding $16 \mathrm{~S}$ rRNA from the halophilic archaebacterium Haloarcula marismortui. Genetics 130, 399-410.

Romano, I., Poli, A., Finore, I., Huertas, F. J., Gambacorta, A., Pelliccione, S., Nicolaus, G., Lama, L. \& Nicolaus, B. (2007). Haloterrigena hispanica sp. nov., an extremely halophilic archaeon from Fuente de Piedra, southern Spain. Int J Syst Evol Microbiol 57, 1499-1503.

Ross, H. N. M. \& Grant, W. D. (1985). Nucleic acid studies on halophilic archaebacteria. J Gen Microbiol 131, 165-173.

Savage, K. N., Krumholz, L. R., Oren, A. \& Elshahed, M. S. (2007). Haladaptatus paucihalophilus gen. nov., sp. nov., a halophilic archaeon isolated from a low-salt, sulfide-rich spring. Int J Syst Evol Microbiol 57, 19-24.

Savage, K. N., Krumholz, L. R., Oren, A. \& Elshahed, M. S. (2008). Halosarcina pallida gen. nov., sp. nov., a halophilic archaeon from a low-salt, sulfide-rich spring. Int J Syst Evol Microbiol 58, 856-860.

Schmidt, H. A., Strimmer, K., Vingron, M. \& von Haeseler, A. (2002). TREE-PUZZLE: maximum likelihood phylogenetic analysis using quartets and parallel computing. Bioinformatics 18, 502-504.

Shimodaira, H. (2002). An approximately unbiased test of phylogenetic tree selection. Syst Biol 51, 492-508.

Shimodaira, H. \& Hasegawa, M. (2001). CONSEL: for assessing the confidence of phylogenetic tree selection. Bioinformatics 17, 12461247.

Stamatakis, A., Ludwig, T. \& Meier, H. (2005). RAxML-III: a fast program for maximum likelihood-based inference of large phylogenetic trees. Bioinformatics 21, 456-463.

Tindall, B. J. (2003). Taxonomic problems arising in the genera Haloterrigena and Natrinema. Int J Syst Evol Microbiol 53, $1697-$ 1698.

Ventosa, A., Gutiérrez, M. C., Kamekura, M. \& Dyall-Smith, M. L. (1999). Proposal to transfer Halococcus turkmenicus, Halobacterium trapanicum JCM 9743 and strain GSL-11 to Haloterrigena turkmenica gen. nov., comb. nov. Int J Syst Bacteriol 49, 131-136.

Walsh, D. A., Bapteste, E., Kamekura, M. \& Doolittle, W. F. (2004). Evolution of the RNA polymerase $\mathrm{B}^{\prime}$ subunit gene $\left(r p o B^{\prime}\right)$ in Halobacteriales: a complementary molecular marker to the SSU rRNA gene. Mol Biol Evol 21, 2340-2351.

Wright, A.-D. G. (2006). Phylogenetic relationships within the order Halobacteriales inferred from 16S rRNA gene sequences. Int J Syst Evol Microbiol 56, 1223-1227.

Xin, H., Itoh, T., Zhou, P., Suzuki, K., Kamekura, M. \& Nakase, T. (2000). Natrinema versiforme sp. nov., an extremely halophilic archaeon from Aibi salt lake, Xinjiang, China. Int J Syst Evol Microbiol 50, 1297-1303.

Xu, Y., Wang, W., Xue, Y., Zhou, R., Ma, Y., Ventosa, A. \& Grant, W. D. (2001). Natrialba hulunbeirensis sp. nov. and Natrialba chahannaoensis sp. nov., novel haloalkaliphilic archaea from soda lakes in Inner Mongolia Autonomous Region, China. Int J Syst Evol Microbiol 51, 1693-1698. 